\title{
Futebol é "coisa para macho"? Pequeno esboço para uma história das mulheres no país do futebol ${ }^{1}$
}

Fábio Franzini

Doutorando em H istória Social - FFLCH/USP

\section{Resum O}

Um dosaspectosmenos conhecidos da história do futebol no Brasil diz respeito à inserção da mulher nesse universo eminentemente masculino. Diante de tal lacuna, este artigo propõe-se a apresentar e analisar as leituras sobre a presença do sexo feminino dentro e fora dos gramados durante a primeira metade do século XX, momento decisivo para a construção da idéia e da identidade do "país do futebol". Pretende-se, assim, discutir as formas de integração ao jogo "permitidas” àsmuIheres, suas manifestações proibidas e, sobretudo, os significados encerrados em tais permissões e proibições.

Palavras-chave: Futebol feminino; Identidadenacional; Gênero e cultura.

\section{ABSTRACT}

The article intents to present and analyze the opinions about Brazilian women's appearance in and out stadiums and fields during the first half of theXXth century, a crucial moment to the construction of the "soccer country" idea and identity. The purpose is to discuss which game integration forms wereallowed to thewomen, which of their manifestation wereforbidden and especially the means inmplicated in that permissions and prohibitions.

Keywords: Women's football in Brazil; National identity; Gender and culture.

Em 1995, quando da realização da segunda Copa do Mundo de Futebol Feminino na Suécia, o então Secretário-Geral da FIFA, J oseph Blatter, lançouse a uma profecia ao afirmar que "o futuro do futebol é feminino. Estamos convencidos de que por volta de 2010 o futebol feminino será tão importante quanto o masculino". ${ }^{2}$ Longe de serem as palavras de alguém interessado em agradar a um público de ocasião, como pode parecer à primeira vista, tal declaração vinha corroborada pela rápida e impressionante expansão desse esporte entre as mulheres, mundial mente registrada a partir da década de 1980. Basta notar que a própria criação da versão feminina da Copa do Mundo é 
fruto desse processo de organização e institucional ização, que em alguns países criou uma estrutura equiparável, quando não superior, à do futebol masculino, como na China e nos Estados Unidos, para citar dois dos casos mais significativos.

No Brasil, entretanto, a presença feminina dentro das quatro linhas ainda busca a sua afirmação. Segundo dados recentes da Confederação Brasileira de Futebol, o país tem cerca de 400 mil jogadoras, número irrisório se comparado ao denossosjogadores profissionais, ou então aos 12 milhões de atletas que pisam os gramados norte-americanos. ${ }^{3}$ Se pensarmos no papel que a bola desempenha enquanto el emento congregador de nossa identidade nacional, tal contraste coloca uma pergunta crucial: qual o lugar da mulher dentro do país do futebol?

É notório que o universo do futebol caracteriza-se por ser, desde sua origem, um espaço eminentemente masculino; como esse espaço não é apenas esportivo, mas também sociocultural, os valores nele embutidos e dele derivados estabelecem limites que, embora nem sempre tão claros, devem ser observados para a perfeita manutenção da 'ordem', ou da 'lógica', que se atribui ao jogo e que nele se espera ver confirmada. A entrada das mulheres em campo subverteria tal ordem, e as reações daí decorrentes expressam muito bem as relações de gênero presentes em cada sociedade: quanto mais machista, ou sexista, ela for, mais exacerbadas as suas réplicas.

Em nosso contexto, sabemos bem quais as respostas produzidas. A virilidade virtuosa do esporte é freqüentemente ressaltada pela sentença "futebol é coisa para macho" (ou, em uma versão pouco menos rude, "coisa para homem"), bem como em tiradas jocosas reveladoras de vivo preconceito. 0 jornalista Sérgio Cabral conta que, perguntado certa vez sobre o que achava do futebol feminino, o comentarista esportivo e ex-técnico J oão Sal danha disse ser contra - e justificou, com sua língua ferina: “I magina, o cara tem um fiIho, aí o filho arranja uma namorada, apresenta a namorada ao sogro e o sogro pergunta a ela: 'O que você faz, minha filha?' $E$ a mocinha responde: 'Sou zagueiro do Bangu'. Quer dizer, não pega bem, não é?". ${ }^{4}$ M esmo as mais recentes tentativas oficiais de incentivo ao futebol feminino no Brasil escorregam no machismo característico de nossa cultura, como foi o caso do Campeonato Paulista Feminino de 2001. À época, reportagem do jornal Folha de S. Paulo revelou que um dos pontos do projeto elaborado pela Federação Paulista de Futebol e pela empresa Pelé Sports \& M arketing para o torneio condicionava seu sucesso a "ações que enalteçam a beleza e a sensual idade da jo- 
gadora para atrair o público masculino". Tradução: calções minúsculos, maquiagem e longos cabelos, presos em rabos-de-cavalo. ${ }^{5}$

Frente a tais posturas e práticas, não surpreende que as mulheres não sejam vistas como mais um sujeito da história do futebol brasileiro, eque o futebol feminino, em particular, seja um tema praticamente inexistente quando se fala sobre a trajetória do chamado "esporte bretão" em nosso país. Dentre as poucas referências encontradas a seu respeito em nossa historiografia futebolística, podemos destacar duas rápidas passagens, separadas por uma diferença de quase meio século. A primeira delas apareceu em 1950, na pioneira História do Futebol no Brasil, obra do jornalista Thomaz M azzoni, e é taxativa: ao mencionar o primeiro confronto entre paulistas e cariocas no Pacaembu, disputado por São Paulo F. C. e América F. C. em 1940, o autor diz que "nesse jogo, como preliminar, foi lançado o futebol feminino, cujo interesse se limitou a esse único jogo. M orreu logo o futebol de moças". M ais recentemente, na década de 1990, o historiador J osé Sebastião Witter afirma, em nota de rodapé ao texto de sua Breve H istória do Futebol Brasileiro, que "no Brasil, o primeiro jogo de futebol feminino de que se tem notícia foi disputado em 1913, entre times dos bairros da Cantareira e do Tremembé, de São PauIo. Cercado de preconceitos, o esporte não chegou a se firmar entre as muIheres, mas a partir de 1981 formaram-se várias equipes femininas em clubes como São Paulo, Guarani, América e outros". ${ }^{6}$

De fato, o "futebol de moças" não chegou a conhecer entre nós o sucesso que al cançara na Europa entre o final da década de 1910 e o início dos anos 20. Na Inglaterra, por exemplo, ele atingiu grande popularidade durante a Primeira Guerra Mundial, quando os homens viram-se obrigados a trocar os campos de jogo pelos de batalha. Forçadas pela necessidade a assumir funções predominantemente masculinas, as mulheres acabaram também por formar equipes e promover jogos beneficentes para levantar fundos para os soldados no front. Com o fim da guerra e a restauração dos papéis sociais tradicionais, esses times femininos entraram em choque com os interesses dos supostos donos do jogo, e logo as mulheres viram-se mais uma vez segregadas às arquibancadas. Já na França, nesse mesmo momento, as futebolistas procuraram não entrar em confronto com os homens e criaram regras particulares para o 'seu' jogo, o que lhes garantiu fôlego até por volta de 1926, porém não conseguiram evitar o mesmo destino de suas colegas inglesas. ${ }^{7}$

Aqui, o processo seguiu mesmo um curso diferente, mas nem por isso ele deixa de representar uma longa e significativa história, ao contrário do que a lacuna historiográfica parece indicar. Se considerarmos não apenas a 
prática do esporte em si mesma, mas também as manifestações a ela associadas, veremos que tal história acompanha o desenvolvimento do futebol no país desde seus primei ros anos, quando as filhas da elite tomavam parte na assistência para ver o desempenho de seus pares dentro das quatro linhas. Tudo de acordo com a etiqueta social da belle-époque, como descreveu o jornalista M ario Filho em seu clássico 0 Negro no Futebol Brasileiro:

O futebol prolongava aquele momento delicioso de depois da missa. As moças, mais bonitas ainda. Tinham ido em casa, demorando-se diante do espelho, ajeitando o cabelo penteado para cima, encacheado.

$\mathrm{Na}$ arquibancada, sentadas, abrindo e fechando os leques, sérias, sorridentes, quietas, nervosas, como que ficavam em exposição ... No intervalo, o campo ea arquibancada tornavam-se uma coisa só. Jogadores e torcedores no bar. Jogadores e torcedores nas arquibancadas. Os jogadores gostavam de aparecer um instante, suados, cansados, na arquibancada, para cumprimentar as moças. N ão se demoravam muito, vinham eiam, as travas das chuteiras rangendo no cimento.

As moças ficavam mais nervosas, aí é que não paravam de abrir efechar os leques. Belos leques, uns grandes, de babados de renda, outros pequenos, de madrepérola. E os pais e as mães perto, achando tudo aquilo muito certo, muito direito.

E tudo estava mesmo muito certo, muito direito. Os filhos no campo, as fiIhas nas arquibancadas. Pais, filhos, a família toda. Podia-se dizer: as famílias todas. $O$ que havia ali, no campo, na arquibancada, havia nos bailes do Clube das Laranjeiras, mais do Fluminense e Paissandu, havia nas festas e festinhas da casa do Barão de Werneck, da casa de dona Chiquitota, da casa dos H ime, mais do Botafogo. ${ }^{8}$

Era uma época em que, ainda de acordo com M ario Filho, "o fotógrafo da Revista da Semana ou da Careta, quando ia a um campo de futebol, era para bater um grupo de moças. Detime, só encomendando, como uma fotografia de formatura". ${ }^{9}$ À medida que o futebol se popularizava, porém, a aristocracia deixava os estádios, levando consigo suas filhas e, em muitos casos, também os filhos. Mudavam os jogadores, que passaram a entrar em campo graças ao talento e não ao sobrenome, mudava também o público, que agora freqüentava mais os gal pões das fábricas que os sel etos salões de baile dos clubes. Nem por isso as mulheres, ainda que outras mulheres, deixaram de acompanhar o futebol, como mostra a presença das jovens M iquelina e Iolanda nas arquibancadas do Parque Antarctica, assistindo à vitória do Corinthians sobre o Palestra no conto de Antônio de Alcântara M achado chamado justa- 
mente "Corinthians (2) x Palestra (1)". ${ }^{10}$ Escrito na década de 1920, o texto demonstra à perfeição como o elitismo e seus bons modos perdiam de vez seu lugar no futebol para a alegria e a vibração populares, com o apelo da bola tornando-se abrangente a ponto de o autor, mesmo na ficção, fazer daquelas torcedoras suas personagens principais.

Anos depois, as mulheres já se levantavam de seus lugares na assistência para adentrar os gramados. Em 1940, a edi ção de abril da revista Educação Física informava a realização de uma "interessante partida de futebol entre senhoritas" no Rio de Janeiro, que "constituiu um espetáculo de grande sucesso, causando assim sensação em nosso mundo desportivo". ${ }^{11}$ Àquela altura, matéria do jornal paulistano Folha da M anhã reconhecia a existência de dez equipes de senhoritas futebolistas "em franca e regular atividade" na capital federal. ${ }^{12} \mathrm{E}$ que não se pense em Flamengo, Fluminense, Botafogo ou Vasco: constituídos nos subúrbios cariocas, o Eva F. C., o E. C. Brasileiro, o Cassino Realengo, o Benfica F. C. estavam muito longe, em todos os sentidos, dos grandes e tradicionais clubes da cidade. As diferenças estruturais entre eles eram tão grandes que, para formar seu quadro de jogadoras, o Primavera F. C. fez publicar num matutino o seguinte anúncio: “M oças de 15 a 25 anos, que queiram ingressar no football, com consentimento dos seus maiores, queiram apresentar-se à rua Silva Gomes, 131, em Cascadura, das 17 em diante". ${ }^{13}$

De imediato, a novidade representada pela aparição e desenvolvimento dessas equipes despertou amores édios no eixo Rio-São Paulo. A Folha da $M$ anhã, por exemplo, dava grande entusiasmado destaque aos jogos das "fiIhas de Eva", vendo neles "um movimento sério, respeitável mesmo para a formação e criação de mais um ramo de atividade para as mulheres". ${ }^{14}$ Porém, alguns zelosos desportistas recebiam com estranheza as notícias que chegavam dos subúrbios cariocas. Tanta estranheza que um deles, um certo José Fuzeira, não relutou em escrever ao presidente Getúlio Vargas para "solicitar a clarividente atenção deV. Ex. para que seja conjurada uma calamidade que está prestes a desabar em cima da juventude feminina do Brasil". E explicava:

Refiro-me, Snr. Presidente, ao movimento entusiasta que está empolgando centenas de moças, atraindo-as para se transformarem em jogadoras de futebol, sem se levar em conta que a mulher não poderá praticar esse esporte violento sem afetar seriamente, o equilíbrio fisiológico das suas funções orgânicas, devido à natureza que a dispôs a ser mãe... 
Ao que dizem os jornais, no Rio já estão formados nada menos de dez quadros femininos. Em S. Paulo e Belo H orizonte também já estão constituindo-se outros. E, neste crescendo, dentro de um ano é provável que, em todo o Brasil, estejam organizados uns 200 clubes femininos de futebol, ou seja: 200 núcleos destroçadores da saúde de 2.200 futuras mães, que, além do mais, ficarão presas de uma mentalidade depressiva e propensa aos exibicionismos rudes e extravagantes; pois, desde que já se chegou à insensatez inqualificável de organizar-se pugnas de futebol com um grupo de cegos a correrem, às tontas, atrás de uma bola cintada de guizos, não será de admirar que o movimento feminino a que nos estamos reportando seja o ponto de partida para, no decorrer do tempo, as fiIhas de Eva se exibirem também em assaltos de luta livre e em justas da "nobre arte", cuja nobreza consiste em dois contendores se esmurrarem até ficarem babando sangue. ${ }^{15}$

Essas preocupações de um cidadão comum, que frisava em sua correspondência não dispor das "credenciais de qualquer autoridade educacional ou científica", fizeram soar o alarme. Da Presidência da República, a carta foi encaminhada à Divisão de Educação Física do M inistério da Educação e Saúde, que, por sua vez, a repassou à sua Subdivisão de M edicina Especializada, onde recebeu não só o parecer favorável da "voz da ciência" como todo o seu apoio na cruzada contra as mulheres futebolistas:

O gesto do Snr. José Fuzeira, determinando o debate sobre uma questão que poderia ter conseqüências nocivas para a saúde de grande número de moças, é digno de todos os louvores.

Efetivamente, o movimento que se esboçou nesta Capital para a formação de vários quadros femininos de futebol, e que tomou corpo com o apoio que alguns jornais cariocas deram, é desses que merecem a reprovação das pessoas sensatas, já pelo espetáculo ridículo que representa a prática do "association" pelas mulheres, como também pelas razões de ordem fisiológica, que desaconselham sumariamente um gênero de atividade física tão violento, incompatível mesmo com as possibilidades do organismo feminino ...

Existe hoje uma interminável bibliografia so bre assuntos referentes à educação física e desportos, sendo todos os autores unânimes em profligar o jogo do "velho esporte bretão" pelas mulheres, por acarretar traumatismos que podem afetar departamentos do organismo feminino especialmente delicados e de importância vital. ${ }^{16}$ 
Ambos, missivista e parecerista, preocupavam-se com os "riscos" que o futebol poderia causar ao "frágil" organismo feminino, principalmente com a possibilidade de afetar sua capacidade reprodutiva. Na mesma linha, e quase ao mesmo tempo, o jornal A Gazeta Esportiva publicava a "opinião autorizada" do doutor Leite de Castro, "o primeiro médico do Brasil que se dedicou especialmente à medicina esportiva". Entre outras coisas, o douto doutor dizia que "não é no futebol quea juventude feminina se aperfeiçoará. Pelo contrário - é o futebol o esporte que lhe trará defeitos e vícios; alterações gerais para a própria fisiologia delicada da mulher, além de outras conseqüências de ordem traumática, podendo comprometer seriamente os órgãos da reprodução (ovário e útero)". ${ }^{17}$

Além do machismo e do moral ismo que essas ditas preocupações com o bem-estar das brasileiras não conseguem esconder, elas revelam que, na verdade, o grande problema dizia respeito não ao futebol em si, mas justamente à subversão de papéis promovida pelas jovens que o praticavam, uma vez que elas estariam abandonando suas "funções naturais" para invadirem o espaço dos homens. Não por acaso, o foco do debate centrava- se nos usos que as muIheres faziam de seu próprio corpo, daí derivando-se o tema da maternidade. Nos anos 30 e 40, a associação entre o autoritarismo político e as idéias eideais da eugenia fazia do corpo uma questão de Estado e o colocava na ordem do dia; segundo Alcir Lenharo, "sobre ele se voltam as atenções de médicos, educadores, engenheiros, professores e instituições como o exército, a I greja, a escola, os hospitais. De repente, toma-se consciência de que repensar a sociedade para transformá-la passava necessariamente pelo trato do corpo como recurso de se alcançar toda a integridade do ser humano". ${ }^{18}$ À mulher caberia, entre outras obrigações, contribuir de forma decisiva com o fortalecimento da nação e o depuramento da raça gerando filhos saudáveis, al go que, pensava-se, só seria alcançado se a mulher preservasse sua própria saúde. Se esta condição não excluía a prática de esportes, é certo que nem todo esporte a ela se adequava.

O futebol feminino, portanto, só poderia mesmo representar um "desvio de conduta" inadmissível aos olhos do Estado Novo e da sociedade brasileira do período, pois abria possibilidades outras além daquelas consagradas pelo estereótipo da "rainha do lar", que incensava a "boa mãe" e a "boa esposa" (de preferência seguindo os padrões hollywoodianos de beleza), principalmente, restrita ao espaço doméstico. ${ }^{19}$ D esvio tão inadmissível que a Subdivisão de M edicina Especializada recomendava que se fizesse uma "campanha de propaganda mostrando os malefícios causados pelo futebol praticado pelas mu- 
Iheres, a fim de evitar lamentáveis conseqüências enquanto se aguarde medidas tendentes a permitir a interferência dos Poderes Públicos em tais questões, medidas estas que muito bem poderiam constar na Regulamentação dos Desportos, presentemente em estudos". ${ }^{20}$

Ao que tudo indica, tal campanha não chegou a ser desencadeada, embora a idéia do parecerista fosse endossada pelo chefe da Divisão de Educação Física, major Barbosa Leite, em observação manuscrita ao final do documento da Subdivisão de M edicina Especializada, datada de 23 de maio de 1940. Nas palavras do major, "seria conveniente interessar o DIP na execução da campanha indicada no parecer, para a qual poderá ser ordenada a cooperação desta Divisão". ${ }^{21}$ No entanto, a sugestão da "interferência dos Poderes Públicos em tais questões" parece ter sido acatada, uma vez que o Decreto-lei 3.199, que em abril de 1941 instituiu o Conselho Nacional de Desportos (CND), afirmava em seu artigo 54 que "às mulheres não se permitirá a prática de desportos incompatíveis com as condições de sua natureza, devendo, para este efeito, o Conselho $\mathrm{N}$ acional de Desportos baixar as necessárias instruções às entidades desportivas do país".22

Ao "proteger" a "natureza feminina", a lei atendia ao apelo daqueles que condenavam a prática do futebol pelas mulheres, eainda deixava a critério do CND a definição de quais esportes elas poderiam praticar. E havia uma série de esportes "recomendáveis", como já mostrava o citado laudo da Divisão de Educação Física do M inistério da Educação e Saúde: tênis, voleibol, críquete, natação, ciclismo - estes doisúltimos desde que "praticados moderadamente", conforme ressalvava o documento. ${ }^{23}$ Todos eles esportes amadores, característicos da elite, que, quando muito, atingiam a classe média, passando ao largo das grandes massas e dos subúrbios onde as jovens corriam atrás da bola.

Por tudo isso, a preliminar de São Paulo eAmérica na noite de 11 de maio de 1940, no recém-inaugurado estádio do Pacaembu, causou enorme indignação em muita gente que acompanhava o futebol. Foi o caso de "H elênico", colunista da Gazeta Esportiva, jornal da capital paulista: às vésperas da partida, por ele caracterizada como "verdadeiro atentado à educação física, ao esporte e mesmo à organização esportiva do nosso Estado", seus brados clamavam por uma intervenção oficial da Diretoria Geral de Esportes no sentido de proibir a realização daquela exibição "cômica". Afinal, segundo ele:

Q uem conhece educação física e sabe, pois, quais os esportes que a mulher pode e deve praticar, dadas as suas condições fisiológicas, pasma ante tal "espetáculo" que se quer levar a cabo. 0 futebol é condenado até para rapazes meno- 
res de 17 anos, e é proibido terminantemente para as mulheres. Qualquer simples monitor de ginástica sabe que a educação física feminina é dosada e é necessário controlá-la. No próprio atletismo, que éo esporte-base por excelência, a mulher só pode praticar determinadas provas, e assim mesmo dentro de normas e cuidados especiais. 0 bola ao cesto praticado pela mulher não éainda muito aconselhável. As próprias leis de jogos são diferentes das masculinas, justamente por ser exaustivo o emprego físico. Somente o tênis e a natação são aconselháveis, assim mesmo com moderação. Agora temos aí o futebol feminino - a última invenção carioca - a querer tentar a sua vida em nossa Capital, dentro de um Estádio Olímpico, que é o do Pacaembu, com um enorme cartaz de propaganda barulhenta! ${ }^{24}$

Deixando de lado o bairrismo das últimas linhas, interessa ressaltar do texto de Helênico a sua sintonia com o discurso médico-científico do momento. Como já foi mencionado, não era então outra voz senão a da mítica Ciência, com "C" maiúsculo, que "condenava”, "aconselhava”, "recomendava”, "aprovava" tudo que se relacionasse ao corpo e às práticas corporais, ao sabor (obviamente dissimulado) do tempero ideológico do poder; se isto não estava explícito nas imprecações do colunista, é porque o recado era de fácil compreensão. Curioso é notar que, "por um imprevisto de última hora", os quadros do Brasileiro e do Cassino Realengo "resolveram não seguir para São Paulo com a delegação do América", e a partida prevista foi substituída por uma peleja entre cronistas esportivos da cidade. 0 jogo apontado por Thomaz Mazzoni como marco do futebol feminino no Brasil aconteceu, na verdade, al guns dias depois, em 17 de maio, quando as futebolistas entraram em campo para fazer a preliminar do confronto entre São Paulo eFlamengo, também no Pacaembu. Nas palavras da Folha da M anhã, o público viveu então “momentos dos mais agradáveis, sobretudo humorísticos, pois, se as frágeis jogadoras não exibiram técnica de futebol, padrão de jogo etc., agradaram em cheio, na maioria das vezes, pelas próprias falhas, que eram recebidas com gostosas gargalhadas pela assistência". 25

Não é possível saber que "técnica" eque "padrão de jogo" o repórter e, a julgar pelo seu relato, todo o público esperavam das 22 jogadoras, mas a ênfase dada às suas "falhas" é reveladora de um olhar adestrado pela prática do futebol enquanto característica masculina. Este era o padrão que definia o jogo, no qual todas as suas manifestações deveriam se encaixar. A comparação era inevitável, como era inevitável que ela colocasse a mulher em uma posição diferenciada frente ao homem, de acordo com as qualidades tidas como 
"ideais" para cada um. A esse propósito, o Dr. Humberto Ballariny, em artigo publicado na edição de dezembro de 1940 da revista Educação Física intitulado justamente "Por que a mulher não deve praticar o futebol", afirmava que "a perfeição feminina não pode ser idêntica à perfeição masculina, logo os meios para al cançá-la devem diferir em certos pontos". O futebol, claro, era um dos componentes de tais pontos, por ser "anti-higiênico e contrário à natural inclinação da alma feminina". ${ }^{26}$ Tantas e tamanhas pressões fizeram com que essa primeira tentativa de organização do futebol feminino no Brasil chegasse a um melancólico fim, assim narrado pela Gazeta Esportiva em janeiro de 1941:

0 futebol feminino vai ter o fim que o aguardava. Existindo unicamente no Distrito Federal, onde nasceu e chegou a tomar vulto, será - ante uma triste exploração aventurada por uma "empresária" sem escrúpulos, seguida, dias depois, da ameaça de se transportar a vergonheira para o Prata - destruído pela polícia carioca, que, embora tardiamente, percebeu o quisto social que tal inovação constituía, resolvendo fechar os clubes de moças e impedir a anunciada ida de um quadro feminino a Buenos Aires. ${ }^{27}$

De acordo com a matéria, a "curiosidade pelo futebol de saias" durara pouco, até porque as moças foram "incapazes de se adaptar às múltiplas dificuldades do esporte-rei". Com a diminuição do interesse, do público e das rendas, o Primavera F. C. - aquele mesmo clube que recrutara jogadoras pelos anúncios classificados - tentava conseguir al guns jogos na capital argentina. Ao mesmo tempo, e, ao que parece, pelos mesmos motivos, "uma gorda matrona sem consciência" tivera a idéia de transformar sua equipe em um grupo de bailarinas que, segundo outra notícia do mesmo jornal, "surgiam nos dancings e cabarets com a mesma indumentária dos campos de futebol: calções curtos, tornozeleiras e chuteiras". Para a moral de então, tais fatos eram um ataque ao esporte nacional e à "família brasileira", tanto que, enquanto a Gazeta celebrava a intervenção das autoridades e o fim da "existência condenável do futebol feminino", o Diário Carioca vibrava com a investigação, pela polícia, das "verdadeiras finalidades desses clubes femininos", qualificados como "antros de perdição" pelo repórter. ${ }^{28}$

De modo geral, não houve sensibilidade para compreender a entrada das mulheres em campo como uma decorrência da popularização do futebol entre nós. Todas as reações a esse movimento, como se viu, foram no sentido de colocá-las "no seu devido lugar", banindo-as de dentro das quatro linhas, es- 
paço próprio ao homem. Para elas, futebol só da arquibancada, e ainda assim em lugares reservados, como se fossem guetos na torcida. N este caso, sua presença nos estádios não só era saudada como estimulada pela imprensa. ${ }^{29} \mathrm{~A}$ relação tolerada das mulheres com o futebol funcionava assim como metáfora de sua posição na sociedade brasileira da época, já que nesta seu papel não era muito diferente de ficar nos reservados da assistência, vendo os homens "construírem a nação".

Depois do cerceamento vivido no início dos anos 40, o futebol feminino no Brasil limitou-se a manifestações esparsas ao longo do tempo, sem chegar sequer a esboçar a constituição de um novo centro irradiador, ou mesmo minimamente estruturado. Isto não significa que tal perspectiva não incomodasse os defensores da moral e dos bons costumes de plantão, uma vez que, logo no início da ditadura militar, o CND proibiu às mulheres “a prática de lutas de qualquer natureza, futebol, futebol de salão, futebol de praia, pólo aquático, pólo, rugby, halterofilismo e baseball". ${ }^{30} \mathrm{~A}$ proibição só veio a ser revogada na década de 1980, e se fez acompanhar da criação de departamentos de futebol feminino em vários clubes do país, bem como do surgimento de equipes como a do Radar, do Rio de Janeiro. Mesmo assim, as dificuldades culturais e materiais persistiram, fazendo com que a prática ora se expandisse, ora entrasse em refluxo. Tanto que nem a conquista do quarto lugar nas Olimpíadas de Atlanta (1996) e de Sydney (2000), ou a medalha de bronze na Copa do Mundo de 1999 bastaram para fixar uma estrutura que guardasse alguma semel hança com a do masculino.

H oje, passado mais de meio século da perseguição promovida pela ditadura estadonovista, a identidade masculina criada e constantemente reafirmada ao longo da história da bola no Brasil faz com que boa parte das muIheres sequer sereconheça no jogo - "coisa de homem", lembremos; ao mesmo tempo, outras enfrentam dificuldades de toda sorte para tentar se afirmar dentro dos gramados, com a bola nos pés. Seja como for, para todas elas o país do futebol assume forma bem diversa daquela consagrada no senso comum: para as primeiras, tal país é um lugar muito distante; para as demais, um lugar de exílio.

\section{NOTAS}

${ }^{1} \mathrm{~A}$ versão original deste texto, que partiu de um tópico pontualmente trabalhado em minha dissertação de mestrado - As raízes do país do futebol: Estudo sobre a relação entre o futebol ea nacionalidade brasileira (1919-1950), orientada pelo Prof. Nicolau Sevcenko e 
que contou com bolsa da Fapesp - , foi apresentada ao Fórum de Pesquisa "Antropologia do esporte: as múltiplas dimensões de uma prática moderna", junto à IV Reunião de Antropologia do M ercosul, realizada em Curitiba (PR) de 11 a 14 de novembro de 2001. Agradeço a todos os colegas participantes pelo debate que me propiciou novas reflexões sobre o tema, que tento aqui apresentar, e em especial à Professora Simoni Lahud Guedes, coordenadora do Fórum.

${ }^{2}$ Apud HEN NIES, R. “Great Expectations for 2010”. Fifa website: www.fifa2.com/scripts/runisa.dll?57:gp::67173+wwc/1995/techrpt/index

${ }^{3}$ Cf. ARRU DA, E. “Amadorismo marcaa modalidadeno Brasil". Fol ha deS. Paulo, 16.09.2001, p.D5.

${ }^{4}$ Episódio lembrado pelo jornalista Sérgio Cabral em debate-homenagem a João Saldanha real izado na Universidade do Estado do Rio de Janeiro em 1990. Apud M URAD, M. "Saldanha, uma saudade". Pesquisa de Campo. Rio de Janeiro, jun. 1994, p.10.

${ }^{5} \mathrm{O}$ título da reportagem de Eduardo Arruda já diz tudo: "FPF institui jogadora-objeto no Paulista". Folha de S. Paulo, 16.09.2001, p.D 5. A matéria traz ainda uma fala do presidente da Federação Paulista, Eduardo J osé Farah, que merece destaque: "Temos que mostrar uma nova roupagem no futebol feminino, que está reprimido por causa do machismo. Temos que tentar unir a imagem do futebol à feminilidade".

${ }^{6}$ M AZZO NI, Th. História do Futebol no Brasil. São Paulo: Leia, 1950, p.289. WITTER, J. S. Breve História do Futebol Brasileiro. São Paulo: FTD, 1996, p.21. É importantenotar quea partida de 1913, apontada por Witter como pioneira, também não escapa à polêmica: recente matéria da Folha deS. Paulo apresenta várias versões para o episódio. Segundo a reportagem, alguns periódicos de época afirmavam que as jogadoras seriam homens travestidos de mulher, enquanto outros diziam que o confronto sedeu entre um timedemulheres e outro de homens; além disso, há ainda, de acordo com a mesma matéria, divergências entre os historiadores tanto no que diz respeito à data de realização da partida (que teria ocorrido em 1921, enão em 1913) quanto em relação ao seu pioneirismo (pois teria havido outros jogos entre equipes femininas antes de 1913). Cf. ASSU M PÇÃO, J. C. "Homens podem ter disputado o 1 - jogo feminino". Folha deS. Paulo, 25.05.2003, p.D5.

${ }^{7}$ Cf. DU KE, V. \& CRO LLEY, L. Football, Nationality and The State. Essex and New York: Longman, 1996, p.132-4. M URRAY, B. U ma H istória do Futebol. São Paulo: H edra, 2000, p.71-2.

${ }^{8}$ RODRIGUES FILHO, M . 0 Negro no Futebol Brasileiro. 2.ed. Rio de Janeiro: Civilização Brasileira, 1964, p.23-4.

${ }^{9}$ Ibidem, p.27.

${ }^{10}$ M ACHAD O, A. deA. "Corinthians (2) x Palestra (1)". Novelas Paulistanas. Belo Horizonte: Itatiaia; São Paulo: Edusp, 1988, p.102-8. 
11 "Futebol feminino no Rio de Janeiro". Educação Física - Revista de Esportes e Saúde. Rio deJaneiro, n.41, abr. 1940, p.65.

${ }^{12} \mathrm{Cf}$. “Em negociações a vinda a esta capital dos quadros femininos do 'Eva' e do 'Brasileiro'", Folha da M anhã, São Paulo, 05.04.1940, p.11.

${ }^{13}$ Reproduzido pela coluna "Pingos e Respingos" do Correio da M anhã, Rio de Janeiro, 28.04.1940, p.2.

14 “Farão ellas o que elles não conseguem?...". Folha da M anhã, São Paulo, 30.03.1940, p.12.

${ }^{15}$ Carta de José Fuzeira ao IImo. Sr. Presidente da República, Dr. Getulio Vargas ( grifos do original). Rio de Janeiro, 25.04.1940. Arquivo Gustavo Capanema - CPDOC/Fundação Getúlio Vargas (RJ): GC 36.04.22/g - Filme 42 - mf. 0117.

16 "Parecer da Sub-divisão de M edicina Especializada a Despacho do Exmo. Snr. Presidente da República", assinado por Paulo Frederico de Figueirêdo Araújo. Rio de Janeiro, 17.05.1940. Arquivo Gustavo Capanema - CPD OC/Fundação Getúlio Vargas (RJ): GC 36.04.22/g - Filme 42 - mf. 0118.

17 "U ma opinião autorizada: não éno futebol que a juventude feminina se aperfeiçoará". A Gazeta Esportiva, São Paulo, 29.06.1940, p.10.

${ }^{18}$ LENH ARO, A. Sacralização da Política. 2.ed. Campinas: Papirus, 1986, p.75.

${ }^{19}$ CARNEIRO, M . L. T. “El universo simbolico de la 'Epoca Vargas': fascinación y seducción de una dictadura". In: SAN CHEZ, J. N. (Ed.) Historia Politica. Quito: Ed. Nacional, s.d., p.247-50. Como a autora afirma às páginas 248-9, "el modelo de mujer colocado en escena no era el de la matrona, ni de la mujer activista política. El lugar de la mujer era la casa ... La mujer debería ser perfecta, moldeada según los valores de una sociedad machista". Tratava-se, portanto, do "en quadramento moralista da mulher", como coloca, por sua vez, Alcir Lenharo: "É notável para uma época em que a luta dos trabalhadores forjou a conquista de ben efícios para a mulher trabalhadora a manifestação cerrada de vozes reacionárias exigindo da mulher a sua volta ao lar, sua moralização dessexualizada como fatores de reordenamento da família". LEN H ARO, A., op. cit., p.102.

20 "Parecer da Sub-divisão de M edicina Especializada a D espacho do Exmo. Snr. Presidente da República", assinado por Paulo Frederico de Figueirêdo Araújo. Rio de Janeiro, 17.05.1940. Arquivo Gustavo Capanema - CPDOC/ Fundação Getúlio Vargas (RJ): GC 36.04.22/g - Filme 42 - mf. 0119.

${ }^{21}$ | bidem.

${ }^{22}$ A pud M ANH ÃES, E. D. Política de Esportes no Brasil. Rio de Janeiro: Graal, 1986, p.134.

${ }^{23} \mathrm{Cf}$. Parecer da Sub-divisão de M edicina Especializada a D espacho do Exmo. Snr. Presidente da República", assinado por Paulo Frederico de Figueirêdo Araújo. Rio de Janeiro, 17.05.1940. Arquivo Gustavo Capanema - CPD OC/ Fundação G etúlio Vargas (RJ): GC 36.04.22/g - Filme 42 - mf. 0118. Vale notar que o parecerista cita como sua referência 
uma pesquisa realizada na Inglaterra em 1921, época em que o futebol feminino começa a ser perseguido nesse país, conforme mencionado anteriormente.

${ }^{24}$ HELÊNICO. “D eve ser proibido!". A Gazeta Esportiva, São Paulo, 06.05.1940, p.2.

25 "Novamente derrotado o S. Paulo por 2 a 0". Folha da M anhã, São Paulo, 18.05.1940, p.12. Sobre o jogo não realizado em 11 de maio, cf. "Um interessante interestadual marcará a inauguração da iluminação do Estádio do Pacaembu". Folha da M anhã, São Paulo, 10.05.1940, p.11; e“Várias esportivas - Pouco provável a ida a S. Paulo dos teams femininos". Correio da M anhã, Rio de Janeiro, 10.05.1940, p.6.

${ }^{26}$ BALLARINY, H. “Por que a mulher não deve praticar o futebol”. Educação Física, Rio de Janeiro, n.49, dez. 1940, p.52. Cabe notar que meses antes, em setembro, o mesmo tema fora abordado nas páginas da revista por Hollanda Loyola, grande nome da área à época, que afirmava não haver inconveniente na prática do futebol pela mulher, desde que subordinado àquilo que chamava de "princípios de natureza fisiológica" - um conjunto de recomendações que diziam respeito tanto à preparação física quanto à adaptação das regras do jogo. Ao encerrar seu texto, porém, 0 autor não deixava de frisar que fazia "sérias restrições à maneira pela qual as nossas patrícias o estão praticando nos subúrbios, absolutamente empírico, sem cuidados médicos e sem princípios fisiológicos, à vontade, pelo entusiasmo do sensacionalismo e pelo prazer da exibição. Assim condenamos o futebol éum mal eum perigo, pode ser a causa de conseqüências imprevisíveis para a sua saúde e acarretar defeitos comprometedores para a el egância e para a beleza". LOYO LA, H. "Pode a mulher praticar o futebol?". Educação Física - Revista de Esportes e Saúde, Rio de Janeiro, n.46, set. 1940, p.20.

27 “Era uma vez o futebol feminino...". A Gazeta Esportiva. São Paulo, 21.01.1941, p.4.

${ }^{28} \mathrm{Cf}$. "O futebol feminino acabou na cadeia...". A Gazeta Esportiva, São Paulo, 16.01.1941, p.5.

${ }^{29} \mathrm{Cf}$., por exemplo, “O elemento feminino nos campos de futebol”. A Gazeta Esportiva, São Paulo, 19.07.1941, p.13.

${ }^{30}$ BRASI L. CON SELH O NACIO NAL DE DESPO RTOS. Deliberação no. 7-65, de 2 deagosto de 1965: Baixa instruções às entidades desportivas do país sobre a prática de desporto pelas mulheres. A pud FARIA JU NIOR, A. G. de. "Futebol, questões de gênero e co-educação". Pesquisa de Campo. Rio de Janeiro, n.2, 1995, p.23.

Artigo recebido em 03/2004. Aprovado em 10/2005 